\title{
PERAN MASIID AT TAQWA WONOGIRI TERHADAP LINTASAN SEJARAH ISLAM DI WONOGIRI
}

\section{Rizqi Bayu Nugroho}

Prodi Arsitektur Fakultas Teknik

Universitas Muhammadiyah Surakarta

e-mail: Rizqibayu15@gmail.com

\section{Andika Saputra}

Prodi Arsitektur Fakultas Teknik

Universitas Muhammadiyah Surakarta

e-mail: Andika.saputra@ums.ac.id

\begin{abstract}
ABSTRAK
Kota Islam adalah kota yang awalnya dibangun pada semasa Nabi Muhammad SAW, dengan mempertimbangkan konsep ideologi kota yang bercorak Islami dan perilaku Nabi Muhammad SAW. Ciri utama kota Islam adalah kehadiran masjid di dalam wilayah kota. Salah satu kota yang menghadirkan bangunan masjid sebagai unsur utama dalam tata ruangnya adalah Kota Wonogiri yang memiliki Masjid At-Taqwa di pusat kota yang berdekatan dengan alun-alun dan kantor bupati. Fokus penelitian ini adalah mengidentifikasi peran Masjid At-Taqwa dalam lintasan sejarah Kota Wonogiri. Penelitian ini menerapkan metode kualitatif-deskriptif dengan teknik pengumpulan data observasi dan wawancara. Hasil penelitian ini mengungkap perluasan peran Masjid At-Taqwa pada dimensi fungsi pendidikan dini yang diselenggarakan di masjid, meliputi pendidikan tingkat PAUD dan TK, selain peningkatan peran peribadatan shalat.
\end{abstract}

KATA KUNCI: Masjid, kota Islam, peran masjid

\section{PENDAHULUAN}

Kota Islam pada awalnya adalah kota yang dibangun semasa Nabi Muhammad SAW, berdasarkan pertimbangan konsep ideologis dari kota yang memiliki corak Islami ataupun dari perilaku Nabi Muhammad SAW. Ciri utama kota Islam adalah hadirnya bangunan masjid. Berdasarkan penjelasan tersebut masjid merupakan unsur penting dalam pembentukan sebuah kota yang bercorak Islami, yang menandakan di daerah tersebut terdapat masyarakat yang beragama Islam.

Di Pulau Jawa bagian tengah terdapat pula ciri khas kota Islam dengan masjid sebagai salah satu unsur pembentuk kotanya. Di antaranya adalah sebagai berikut :

1) Masjid Gedhe Kauman Jogja yang dibangun pada 29 Mei 1773, pada masa pemerintahan Sultan Hamengkubuwono (HB) I dan Kiai Fakih Ibrahim Diponingrat. Masjid ini dibangun sebagai kelengkapan kerajaan Mataram yang beragama Islam dan merupakan pusat penyebaran agama Islam di Keraton Yogyakarta.

2) Masjid Agung Surakarta yang dibangun oleh Pakubuwono ke 3 pada sekitar tahun 1749. Letaknya di sekitar Alun-alun Utara Keraton Surakarta, tepatnya di bagian barat. Masjid ini memiliki sejarah penting dalam penyebaran Agama Islam di Surakarta.

Dua contoh di atas menjelaskan bahwa masjid bukan saja merupakan unsur utama pembentuk kota Islam, tetapi lebih dari itu keberadaan masjd merupakan unsur utama penyebarluasan agama Islam dan pembentuk sejarah umat Islam.

Kota Wonogiri adalah salah satu kota di Provinsi Jawa Tengah, yang dari segi kesejarahannya memiliki hubungan erat dengan Keraton Mangkunegaran Surakarta. Sejarah terbentuknya Kabupaten Wonogiri tidak dapat dilepaskan dari perjalanan hidup dan perjuangan Raden Mas Said atau yang memiliki julukan sebagai Pangeran Sambernyawa. Asal kata Wonogiri itu sendiri berasal dari Bahasa Jawa Wono (alas/hutan/sawah) dan Giri (gunung/ pegunungan).

Perkembangan sejarah menyebutkan bahwa telah terjadi masalah internal di dalam Keraton Mangkunegaran, yang menyebabkan Raden Mas Said bersama para pengikutnya hijrah mencari daerah yang aman untuk menyusun strategi. Daerah yang dituju ketika itu adalah Dusun Nglaroh yang berada di wilayah Kecamatan Selogiri. Peristiwa ini merupakan awal mula terbentuknya pemerintahan dan menjadi cikal bakal Kabupaten Wonogiri. Penanda bahwasanya Wonogiri memiliki sejarah seorang pemimpin Muslim yang taat dan secara demografis mayoritas warganya beragama Islam, maka didirikanlah Masjid At-Taqwa Wonogiri atau sering disebut Masjid Taqwa di pusat kota Wonogiri.

Masjid Agung At-Taqwa merupakan salah satu masjid tertua di Wonogiri yang dibangun pada tanggal 27 September 1927 oleh pihak Pura Mangkunegaran. Masjid At-Taqwa memiliki luas area $3.600 \mathrm{~m}^{2}$, luasan bangunan $1.020 \mathrm{~m}^{2}$ dengan spesifikasi dua lantai, dan dilengkapi dengan menara adzan. 
Berdasarkan uraian tersebut, maka penelitian ini menjadi penting untuk mengkaji lebih dalam peran Masjid At-Taqwa Wonogiri, yang merupakan salah satu simbol bersejarah di Kabupaten Wonogiri dan menjadi ikonik pembentukan kota Wonogiri. Tujuan penelitian ini adalah untuk mengetahui peran Masjid At-Taqwa Wonogiri terhadap pembentukan sejarah Islam dan syiar Islam dalam lintasan sejarah kota Wonogiri.

\section{LANDASAN TEORI}

Optimalisasi peran masjid sebagai pusat pembinaan umat tidak mungkin dapat dikelola oleh satu atau sekelompok kecil orang, tetapi harus melibatkan semua komponen. Berdasarkan pengertian peran oleh Soerjartono Soekamto (2009) dan pengertian masjid oleh Syekh Said bin Wahf Al-Qahthari diketahui bahwa variabel untuk mengidentifikasi peran masjid terdiri dari (1) kegiatan; (2) pelaku; dan (3) ruang.

Untuk mengoptimalkan peran dan fungsi sebuah masjid dibutuhkan beberapa kegiatan untuk diselenggarakan antara lain (Supriyanto, 2014):

1. Sebagai sarana dakwah.

Nabi memfungsikan masjid bukan sekedar sebagai tempat ibadah, shalat, dzikir, membaca Al-Qur'an dan iktikaf, tetapi Nabi juga memfungsikan masjid sebagai sebuah tempat di mana bertemunya kepentingan dunia dan kepentingan akhirat umat Islam.

2. Sebagai sarana pengembangan kebudayaan.

Struktur atau tata-letak Keraton Yogyakarta dengan Surakarta, identik dengan pola segitiga, meliputi istana, alun-alun, dan fasilitas ibadah (masjid) yang merupakan perwujudan dari kesatuan raja-rakyat dan agama. Gagasan ini tidak dapat dilepaskan dari kebudayaan Jawa, sehingga dapat disimpulkan bahwa kebudayaan Jawa juga ikut berperan dan membawa pengaruh dalam perkembangan masjid dari segi kegiatan maupun arsitekturalnya.

3. Pusat Ibadah.

Masjid merupakan simbol bukan hanya sebagai tempat beribadah kepada Allah, tetapi masjid juga merupakan titik tolak bagi sebuah pondasi terwujudnya peradaban Islam. Masjid berfungsi sebagai pusat Islam, meliputi pusat ibadah dan kebudayaan Islam.

Untuk mampu merealisasikan peran masjid, dibutuhkan pelaku atau pihak yang menggunakan dan menjaga masjid, yaitu antara lain:

1. Jamaah masjid, yakni umat Islam yang melakukan aktivitas, baik sosial ataupun kegiatan spiritual di masjid. Terhitung pula sebagai jamaah masjid ialah orang-orang yang berkunjung dan memiliki keperluan di masjid, baik itu bersifat rutin ataupun momentual, serta pengunjung yang bekerja dan berada di sekitar area masjid.

2. Takmir masjid, yakni orang-orang yang ditunjuk untuk mengelola masjid, baik bersifat profesional maupun relawan yang bertanggung jawab untuk mengurus dan menjalankan peran masjid.

Selain aspek kegiatan dan pelaku, untuk merealisasikan peran masjid diperlukan ruang-ruang yang mampu mewadahi kegiatan pelaku di masjid, di antaranya sebagai berikut:

1. Ruang utama, yakni ruang yang digunakan untuk melaksanakan ibadah shalat wajib, shalat Jumat, kegiatan di bulan Ramadan, maupun kegiatan dalam rangka Hari Besar Islam.

2. Ruang penunjang, yakni ruang yang digunakan untuk mewadahi kegiatan yang bersifat sosialkemasyarakatan, maupun ruang-ruang untuk keperluan shalat, seperti ruang wudhu.

\section{METODE PENELITIAN}

Metode yang digunakan dalam penelitian ini adalah deskriptif kualitatif, yang berfokus pada mengungkap peran Masjid At-Taqwa dalam lintasan sejarah Islam di kota Wonogiri. Teknik pengumpulan data yang digunakan dalam penelitian ini meliputi (1) observasi untuk mengamati peran masjid berdasarkan 3 variabel (kegiatan, pelaku dan ruang); dan (2) wawancara kepada pihak yang memiliki data terkait objek penelitian maupun terlibat dalam peran kesejarahan Masjid At-Taqwa.

\section{Profil Masjid At Taqwa Wonogiri}

Masjid At-Taqwa Wonogiri terletak di Jalan KH. Ahmad Dahlan yang merupakan jalan utama ke arah Sukoharjo dan Surakarta. Masjid At-Taqwa Wonogiri mulai didirikan pada tahun 1927 yang pada awalnya berstatus milik Pura Mangkunegaran hingga akhirnya diambil alih oleh Pemerintah Daerah Wonogiri karena merupakan salah satu simbol bersejarah kota Wonogiri (Gambar 1).

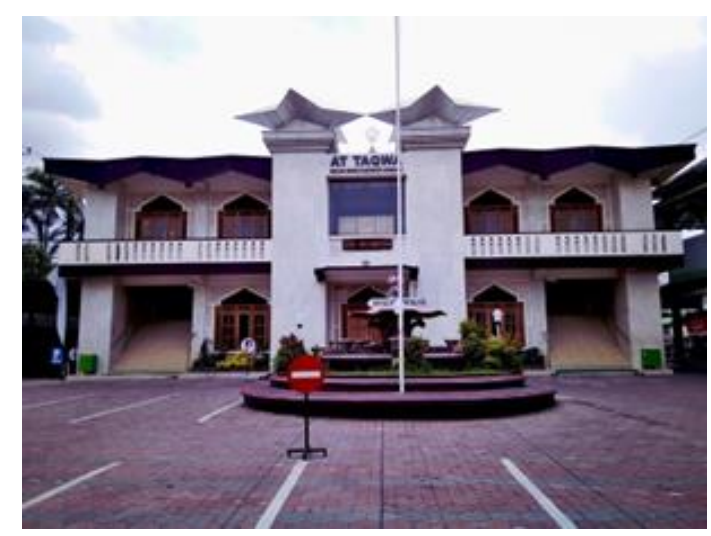

Gambar 1. Masjid At-Taqwa Wonogiri (Sumber: Dokumentasi penulis, 2019) 
Pada masa awal berdirinya, Masjid At-Taqwa memiliki spesifikasi satu lantai hingga pada masa pemerintahan Bupati Oermarsono mulai dilakukan perombakan bentuk dan penambahan lantai, sehingga kini masjid memiliki spesifikasi dua lantai. Maksud dilakukannya perombakan didasari mandat dari Presiden Soeharto agar didirikan masjid paripurna di seluruh Indonesia. Adapun pengertian masjid paripurna ialah bangunan masjid atau tempat ibadah yang juga mengutamakan dan mengedepankan sistem pendidikan nasional. Berdasarkan mandat presiden, dibangun sekolah TK (Taman Kanak-kanak) dan PAUD (Pendidikan Anak Usia Dini) bersamaan dengan perombakan masjid yang masih digunakan hingga sekarang.

\section{HASIL DAN PEMBAHASAN}

Untuk menjelaskan peran Masjid At-Taqwa Wonogiri ditentukan berdasarkan variabel ruang, pelaku, dan kegiatan, yang dibatasi realisasinya pada tahun 1992 yang merupakan era Bupati Oermarsono, sampai tahun 2019 era Bupati Joko Sotopo.

\section{Peran Masjid pada Tahun 1992}

Tabel 1 merupakan data yang teridentifikasi terkait 3 variabel peran masjid di tahun 1992

Tabel 1. Peran Masjid Tahun 1992

\begin{tabular}{ccc}
\hline \multicolumn{1}{c}{ Variabel } & \\
\hline Kegiatan & Pelaku & Ruang \\
\hline $\begin{array}{l}\text { 1.Salat } \\
\text { 2. Akad nikah }\end{array}$ & $\begin{array}{c}\text { 1. Jemaah } \\
\text { shalat }\end{array}$ & $\begin{array}{l}\text { 1. Perluasan ruang } \\
\text { salat }\end{array}$ \\
$\begin{array}{c}\text { 3.Sekolah } \\
\text { 4. Kajian }\end{array}$ & 2. Pasangan & 2. Perombakan \\
agama & pernikahan & bentuk \\
5. Pertemuan & sekolah & bangunan \\
takmir & 4. Santri dan & 3. Rumah ustadz \\
6. Kegiatan & ustadz & 4. Kantor \\
belajar & 5. Takmir & administrasi \\
mengajar & 6. Petugas & masjid \\
& keamanan & 5. Sekolah Paud \\
& dan & 6. Pembangunan \\
& kebersihan & menara
\end{tabular}

Penekanan peran masjid pada tahun 1992 adalah peningkatan bentuk arsitektural masjid sebagai landmark kota dengan melakukan perombakan bentuk bangunan masjid, perluasan fungsi ibadah dengan memperluas bangunan masjidsecara vertikal menjadi 2 lantai yang diperuntukkan bagi kenyamanan dalam pelaksanaan ibadah shalat. Tujuan lain adalah pengenalan fungsi pendidikan di masjid dengan dibangunnya sekolah PAUD bersamaan dengan dibangunnya rumah ustadz dan para santri.
Masjid At-Taqwa Wonogiri pada awalnya memiliki spesifikasi 1 lantai, kemudian dirombak menjadi 2 lantai oleh DPU (Dinas Pekerjaan Umum). Dikarenakan proses pengerjaan yang belum selesai, Bupati Oermarsono meminta BAPENSI (Gabungan Pelaksana Konstruksi Nasional Indonesia) untuk menyelesaikan pengerjaan perombakan masjid. Kegiatan perombakan masjid pada periode ini mendapatkan bantuan dana dari pemerintah pusat. Perubahan bentuk masjid dapat diamati dalam Gambar 2.

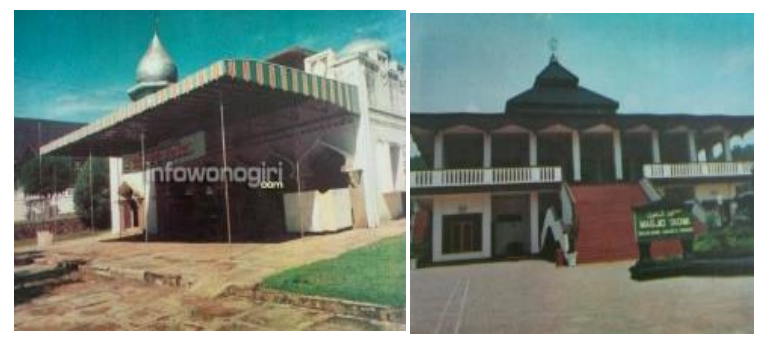

Gambar 2. Perubahan bentuk Masjid At-Taqwa Wonogir (Sumber: www.infowonogiri.com, 2019)

Latarbelakang pendirikan fasilitas pendidikan di Masjid At-Taqwa disampaikan oleh Bapak H.Purwanto selaku takmir lama dan petugas bagian Perencanaan dan Pengembangan Masjid yang menyatakan bahwa,

“...di sini (masjid) dulu pernah ada edaran pada masa pemerintahan Presiden Soeharto, yaitu suatu masjid bisa disebut sebagai masjid paripurna jika selain digunakan sebagai tempat ibadah juga mengutamakan pendidikan, makanya di sini didirikan PAUD dan TK".

\section{Peran Masjid pada Tahun 2013}

Tabel 2 merupakan data yang teridentifikasi terkait 3 variabel peran masjid di tahun 2013.

Tabel 2. Peran Masjid Tahun 2013

\begin{tabular}{|c|c|c|}
\hline \multicolumn{3}{|c|}{ Variabel } \\
\hline Kegiatan & Pelaku & Ruang \\
\hline 1.Salat & 1. Jamaah shalat & 1. Perombakan \\
\hline $\begin{array}{l}\text { 2.Pengajian } \\
\text { rutin }\end{array}$ & $\begin{array}{l}\text { 2. Pasangan } \\
\text { pernikahan }\end{array}$ & $\begin{array}{l}\text { bentuk } \\
\text { desain }\end{array}$ \\
\hline $\begin{array}{l}\text { 3. Kajian } \\
\text { agama }\end{array}$ & $\begin{array}{l}\text { 3. Murid Paud } \\
\text { dan TK }\end{array}$ & $\begin{array}{l}\text { tampak } \\
\text { depan masjid }\end{array}$ \\
\hline $\begin{array}{l}\text { 4.Pertemuan } \\
\text { takmir }\end{array}$ & $\begin{array}{l}\text { 4. Santri dan } \\
\text { ustadz }\end{array}$ & $\begin{array}{l}\text { 2. Perubahan } \\
\text { bentuk ruang }\end{array}$ \\
\hline 5. Kegiatan & 5. Takmir & di lantai 1 \\
\hline $\begin{array}{l}\text { belajar } \\
\text { mengajar }\end{array}$ & $\begin{array}{l}\text { 6. Petugas } \\
\text { keamanan dan } \\
\text { kebersihan }\end{array}$ & $\begin{array}{l}\text { 3. Didirikan } \\
\text { bangunan TK }\end{array}$ \\
\hline
\end{tabular}

Penekanan peran masjid pada tahun 2013 adalah peningkatan kembali bentuk arsitektural masjid dengan melakukan perombakan tampak depan 
bangunan masjid, peningkatan fungsi ibadah dengan perluasan ruang shalat lantai 1 , dan peningkatan fungsi pendidikan di masjid dengan dibangunnya sekolah TK.

Menurut Bapak H. Purwanto, perombakan tampak depan bangunan masjid bertujuan untuk melengkapi masjid dengan 2 akses pintu masuk untuk memisahkan jamaah putri dan jamaah putra agar tidak saling bersentuhan ketika memasuki maupun keluar masjid.

Selain tampak depan masjid yang mengalami perubahan, pada periode ini juga dilakukan perluasan ruang shalat di lantai satu untuk mewadahi jumlah jamaah yang melimpah ketika penyelenggaraan shalat Jumat (Gambar 3).

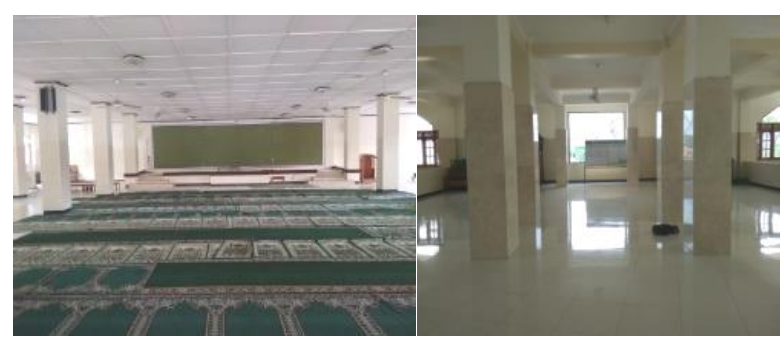

Gambar 3. Perluasan ruang shalat di lantai 1 (Sumber: Dokumentasi penulis, 2019)

\section{Peran Masjid pada Tahun 2019}

Peran masjid At Taqwa di tahun 2019 berdasarkan variable kegiatan, pelaku dan ruang, terdapat dalam tabel 3.

Tabel 3. Peran Masjid Tahun 2019

\begin{tabular}{|c|c|c|}
\hline \multicolumn{3}{|c|}{ Variabel } \\
\hline Kegiatan & Pelaku & Ruang \\
\hline 1.Shalat & 1. Jamaah shalat & 1. Perluasan \\
\hline 2.Pengajian rutin & 2. Pasangan & TK \\
\hline 3.Kajian agama & pernikahan & 2. Dibangun \\
\hline $\begin{array}{l}\text { 4.Pertemuan } \\
\text { takmir }\end{array}$ & $\begin{array}{l}\text { 3. Murid PAUD } \\
\text { dan TK }\end{array}$ & $\begin{array}{l}\text { area } \\
\text { bermain di }\end{array}$ \\
\hline $\begin{array}{l}\text { 5. Kegiatan } \\
\text { belajar } \\
\text { mengajar }\end{array}$ & $\begin{array}{l}\text { 4. Santri dan } \\
\text { ustadz } \\
\text { 5. Takmir }\end{array}$ & samping TK \\
\hline $\begin{array}{l}\text { 6. Latihan drumb } \\
\text { band }\end{array}$ & $\begin{array}{l}\text { 6. Keamanan } \\
\text { dan } \\
\text { kebersihan }\end{array}$ & \\
\hline
\end{tabular}

Penekanan peran masjid pada tahun 2019 adalah perluasan dan peningkatan fungsi pendidikan di masjid dengan memperluas bangunan TK dan menambah fasilitas area bermain untuk proses pembelajaran PAUD dan TK (lihat Gambar 4). Keberadaan fasilitas pendidikan untuk anak anak ini sangat mendukung program menjadikan masjid At Taqwa sebagai masjid paripurna, sebagaimana yang telah disampaikan oleh Bapak Presiden RI H. Soeharto.

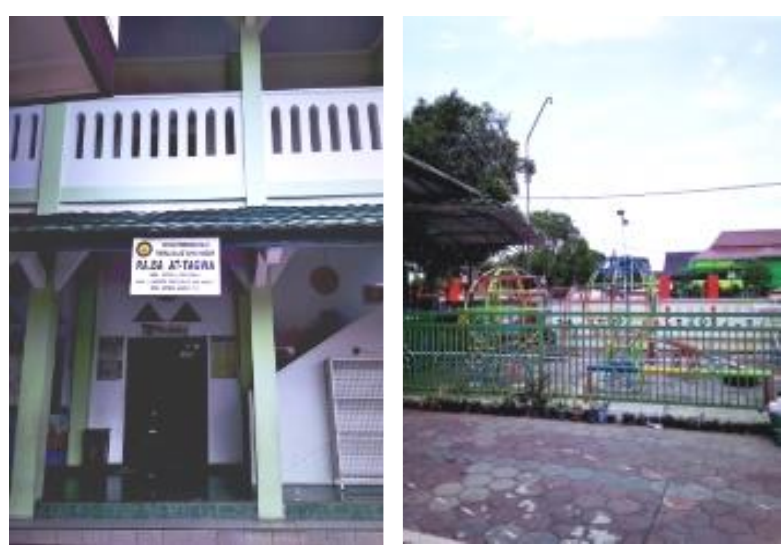

Gambar 4. Bangunan TK dan area bermain anak (Sumber: Dokumentasi penulis, 2019)

\section{KESIMPULAN}

Hasil temuan dari kegiatan penelitian ini dapat disimpulkan bahwa keberadaan Masjid At-Taqwa sejak tahun 1992 hingga tahun 2019 mengalami perluasan peran pada aspek pendidikan Islam tingkat dini, meliputi PAUD dan TK yang diselenggarakan di area masjid. Perluasan peran ini dilihat dari didirikannya fasilitas pendidikan dan kehadiran pelaku pendidikan, meliputi para guru, murid, dan wali murid, serta dilaksanakannya kegiatan pendidikan di area masjid.

Selain itu, Masjid At-Taqwa sebagaimana masjidmasjid lainnya juga mengalami peningkatan peran ibadah shalat yang ditandai dengan perluasan ruang shalat dari 1 lantai menjadi 2 lantai, dan perluasan ruang shalat di lantai 1 untuk mewadahi jumlah jamaah yang terus bertambah, terutama pada saat pelaksanaan shalat Jumat.

\section{DAFTAR PUSTAKA}

, 2015. Sekelumit Sejarah Masjid At Taqwa Wonogiri.https://infowonogiri.com/baca/ wonogiri-hari-ini/2015/08/sekelumit-sejarahmasjid-at-taqwa-wonogiri/ diakses pada $19 \mathrm{Mei}$ 2019.

2018. Masjid Agung Taqwa Menjadi Simbol Historis Islam. http://suarabaru.id/2018/07/26/ masjid-agung-at-taqwa-menjadi-simbol-historisislam/ diakses pada 19 Mei 2019.

Gazalba, Sidi. 1983. Masjid, Pusat Ibadat dan Kebudayaan Islam. Jakarta: Pustaka Antara.

Supriyanto, Juni., 2014. Optimalisasi Fungsi Masjid. https://cyberdakwah.com/2014/05/enamkegiatan-sebagai-optimalisasi-fungsi-masjid, diakses pada 30 Mei 2019.

Pemerintah Kabupaten Wonogiri. 2014. Sejarah Singkat Kabupaten Wononogiri. https://www.wonogirikab.go.id/. diakses pada 16 April 2019 
